1990 National Hospital Discharge Survey. J Am Board Fam Pract 1998;11:187-92.

4. Ciocon JO, Silverstone FA, Graver LM, Foley CJ. Tube feedings in the elderly. Indications, benefits, and complications. Arch Intern Med 1988;148:429-33.

5. Rabeneck L, Wray NP, Petersen NJ. Long-term outcomes of patients receiving percutaneous endoscopic gastrostomy tubes. J Gen Intern Med 1996; 11:287-93.

6. Pick N, McDonald A, Bennett N, Litsche M, Dietsche L, Legerwood R, et al. Pulmonary aspiration in a long-term care setting: clinical and laboratory observations and an analysis of risk factors. J Am Geriatr Soc 1996;44:763-8.

7. Golden A, Beber C, Weber R, Kumar V, Musson N, Silverman $M$, et al. Long-term survival of elderly nursing home residents after percutaneous endoscopic gastrostomy for nutritional support. Nurs Home Med 1997;5:382-9.

8. Kohn M, Menon G. Life prolongation: views of elderly outpatients and health care professionals. J Am Geriatr Soc 1988;36:840-4.

9. Brody H, Campbell ML, Faber-Langendoen K, Ogle KS. Withdrawing intensive life-sustaining treatment- recommendations for compassionate medical management. N Engl J Med 1997;336:652-7.

10. Lee MA, Ganzini L, Brummel-Smith $K$. When patients ask about assisted suicide. A viewpoint from Oregon. West J Med 1996;165:205-8.

11. Solomon MZ, O'Donnell L, Jennings B, Guilfoy V, Wolf SM, Nolan K, et al. Decisions near the end of life: professional views on life-sustaining treatments. Am J Public Health 1993;83:14-23.

12. Levine $S$. Who dies? An investigation of conscious living and conscious dying. New York: Anchor Books, Doubleday, 1989.

\section{Alternative Medicine and the Family Physician}

Complementary and alternative medicine is a subset of health care practices that are not an integral part of the dominant health care system in the United States. ${ }^{1}$ Operationally, complementary and alternative medicine is defined as those health care practices used for the prevention and treatment of disease that neither are taught widely in medical schools nor are generally available in hospitals. ${ }^{2}$

Alternative medicine is an area of great public

Submitted 11 March 1998.

From the Office of Alternative Medicine, National Institutes of Health, Bethesda, Md. Address reprint requests to Wayne B. Jonas, MD, Office of Alternative Medicine, National Institutes of Health, 31 Center Dr, Building 31, Room 5B38, Mail Stop 2182, Bethesda, MD 20892. interest and activity, both nationally and worldwide. One of every three Americans saw an alternative health care practitioner in 1990, amounting to more than 400 million visits, more than to all conventional primary care physicians. More than $\$ 13$ billion were paid for these services, of which $\$ 10$ billion was out-of-pocket and not reimbursed. ${ }^{2}$ In Europe, regular use of complementary and alternative practices ranges from 20 to 70 percent. ${ }^{3}$ and nearly 40 percent in Australia. ${ }^{4}$ According to the World Health Organization, 80 percent of the health care services in the developing world are traditional medicine. ${ }^{5}$ These practices become complementary, alternative, or unconventional when used in Western countries. Recent surveys indicate that the use of complementary and alternative medicine is increasing. ${ }^{6}$

National surveys, however, though useful for understanding public health issues, can be misleading for physicians who deal with local populations or special groups. For example, up to 50 percent of patients who have cancer ${ }^{7}$ or are infected with human immunodeficiency virus ${ }^{8}$ will use unconventional practices at some point during the course of their illness. Folk medicine use in rural and special ethnic populations can exceed 70 percent, ${ }^{9}$ but in certain pediatric populations use of complementary and alternative medicine is around 10 percent. ${ }^{10}$

Although these population and condition-based surveys have documented widespread use of these practices, we know little about how frequently alternative medicine is used in the average family practice population, where a large portion of chronic disease care occurs. Information about the frequency, conditions, and reasons for use of complementary and alternative medicine by patients cared for in family practice can help the physician address these issues with patients more systematically and rationally. Thus, local surveys and surveys of special populations are needed. In this issue of the $7 A B F P$, Drs. Christine Drivdahl and William Miser ${ }^{11}$ report findings of a survey of a military family practice population that asked about the use, perceived effectiveness, and satisfaction of complementary and alternative medicine.

Drivdahl and Miser's report is a descriptive analysis of 177 (of 250) questionnaires randomly sent to persons eligible for care at a military family practice clinic in Washington state. The data showed that more than 28 percent of patients reported ever using alternative medicine. Examples 
were given, but no distinction was made between over-the-counter self-care and visits to professional complementary and alternative medicine practitioners. The respondents were fairly representative of the military population and were generally well educated, married, in good health, and quite satisfied with their care from the family practice clinic. Given these characteristics, the patient satisfaction level, and that their medical care was free, one would expect they had little reason to go elsewhere. Indeed, the rate of complementary and alternative medicine use in this population was lower than that found in many other surveys, though not insubstantial. Consistent with other surveys, those using alternative medicine in this sample were mostly white, educated, and female. Of note, however, is that more than 38 percent of Asians used complementary and alternative medicine.

The results from this survey reflect characteristics unique to this population, and the reader should not generalize these data to all patient or even family practice patient populations. First, the sample was small and designed to capture not those using the medical clinic at the time but only those eligible for care at the clinic. A consecutive survey of patients coming into the family practice clinic would be more representative of what physicians are likely to see.

Second, the high level of patient satisfaction with the care at the clinic is not surprising, because the questionnaires were sent back to the same clinic. This design feature might have biased the responses to those patients who were willing to return the questionnaire and report on such satisfaction. It is difficult in any case to assess satisfaction with care from a single, cross-sectional survey.

Third, the questions and method of obtaining responses in this survey are not the same as those used in national surveys, so the responses are expected to be quite different. Finally, statistically significant $P$ values should not be given much weight in this study because when multiple $P$ values are calculated without some adjustment for multiple testing, it would not be unusual to find some below $P=0.05$. In fact, a number of differences found between the groups appear to be important but did not make the arbitrary $P$ value cutoff.

Little information is given about the rank or time in military service of those who responded and whether they were active-duty or retired personnel. This information could make quite a difference in what is reported. For example, most patients using complementary and alternative medicine suffered from back pain and had sought out chiropractic care. Active-duty personnel are required to pass semiannual physical testing and, if unable to complete such testing successfully, could be discharged from the service. Because chiropractic care would not be reimbursed and few activeduty military have supplementary medical insurance, patient pressure for a quick fix and resentment at having to pay for such services might have prevented or disrupted the normal trust-building relationship often developed between a patient and a complementary or alternative medicine practitioner. ${ }^{12}$ In addition, such dissatisfaction is inconsistent with other surveys showing a high degree of satisfaction with complementary and alternative medical care, especially chiropractic care. ${ }^{6}$

It is not unusual for osteopathic physicians in military clinics to do soft tissue manipulation for musculoskeletal problems, but this service is usually not advertised or known by many patients or even other physicians in the clinic. Finally, because more women than men make use of medical services (both conventional and complementary), and the randomization procedure in this study was designed to balance male and female responses, the overall estimate for complementary and alternative medicine use is likely to be lower than the average use rate for patients coming into the clinic for care.

The more than 70 percent of patients in national surveys who use complementary and alternative medicine and do not tell their conventional physician about that use ${ }^{13}$ is comparable to the 63 percent in this survey. This finding is indicative of a major communication gap between physicians and the public about complementary and alternative medicine. Patients use alternative practices because it is part of their social network, because they are not satisfied with the process or the result of their conventional care, or because they have an attraction to the philosophies and health beliefs associated with complementary and alternative medicine. ${ }^{14}$ More than 80 percent of those who use unconventional practices do so along with conventional medicine. ${ }^{13}$ Patients who use unconventional medicine are not unconventional patients. They do not foster general antiscience or anticonventional medicine sentiment or represent a disproportionate number of those who are uned- 
ucated, poor, seriously ill, or neurotic. ${ }^{7,14,15}$

The physician has a responsibility to help fill this communication gap by asking patients about their use of complementary and alternative medicine and working with their patients to assure they approach such care in a responsible manner. ${ }^{16}$ Uncritical acceptance or rejection of complementary and alternative medicine as whole is not logical, nor will it foster rational communication with patients. Instead, physicians should become familiar with the basic concepts, distinguishing features, and research basis of the main unconventional practices. In addition, physicians need to know to which practitioners of responsible complementary and alternative medicine they can refer patients for specific services, when appropriate. ${ }^{17}$ Learning about unconventional medical practices will become increasingly important to the practice of medicine in the future. Finding high-quality research on these practices can help the physician in decision making about complementary and alternative medicine. When no such research is exists, providing this fact can also be useful for many patients. ${ }^{18}$

To address the increasing need for information and research in complementary, alternative, and unconventional medical practices, Congress created the Office of Alternative Medicine (OAM) at the National Institutes of Health (NIH) in 1992. The OAM is working with NIH institutes and centers to stimulate research activities, support new collaborative initiatives with the institutes and centers, and track, summarize and help encourage research in complementary and alternative medicine. Information from the NIH can serve as a resource for physicians interested in learning more about research on topics in complementary and alternative medicine. Information can be obtained from its Website at http://www.altmed.od.nih.gov or by calling the toll free public information clearinghouse at 1-888-644-6226.

As the interest in and importance of complementary and alternative medical practices continue to grow, physicians will be increasingly called upon to address these areas. Physicians cannot become knowledgeable about all complementary and alternative medicine practices, but they can apply to it the principles of evidence-based medicine as in any area of health care. ${ }^{19}$

$$
\begin{array}{r}
\text { Wayne B. Jonas, MD } \\
\text { Bethesda, Md }
\end{array}
$$

\section{References}

1. Working Group on Definitions and Descriptions of Complementary and Alternative Medicine. Defining and describing complementary and alternative medicine. Alternative Ther Health Med 1997;3(2):49-57.

2. Eisenberg DM, Kessler RC, Foster C, Norlock FE, Calkins DR, Delbanco TL. Unconventional medicine in the United States. Prevalence, costs, and patterns of use. N Engl J Med 1993;328:246-52.

3. Fisher P, Ward A. Complementary medicine in Europe. Br Med J 1994;309:107-11.

4. MacLennan AH, Wilson DH, Taylor AW. Prevalence and cost of alternative medicine in Australia. Lancet 1996;347:569-73.

5. Farnsworth NR, Akerele O, Bingel AS, Soejarta DD, Guo Z. Medicinal plants in therapy. Bull World Health Organ 1985;63:965-81.

6. The Landmark report on public perceptions of alternative care. Sacramento, Calif: Landmark Healthcare, 1998.

7. Cassileth BR, Lusk EJ, Strouse TB, Bodenheimer BJ. Contemporary unorthodox treatments in cancer medicine. A study of patients, treatments, and practitioners. Ann Intern Med 1984;101:105-12.

8. Anderson $\mathrm{WH}$, O'Connor BB, MacGregor RR, Schwartz JS. Patient use and assessment of conventional and alternative therapies for HIV infection and AIDS. AIDS 1993;7:561-5.

9. Risser AL, Mazur LJ. Use of folk remedies in a Hispanic population [see comments]. Arch Pediatr Adolesc Med 1995;149:949-50.

10. Spigelblatt L. Alternative medicine: a pediatric conundrum. Contemp Pediatr 1997;14(8):51-61.

11. Drivdahl CE, Miser WF. The use of alternative health care by a family practice population. J Am Board Fam Pract 1998;11:193-9.

12. Oths K. Communication in a chiropractic clinic: how a D.C. treats his patients. Culture, Medicine \& Psychiatry 1994;18:83-113.

13. Eisenberg DM. The invisible mainstream. Harvard Medical Alumni Bull Summer 1996:20-25.

14. Furnham A, Forey J. The attitudes, behaviors and beliefs of patients of conventional vs. complementary (alternative) medicine. J Clin Psychol 1994;50:458-69.

15. Vincent $C$, Furnham A, Willsmore $M$. The perceived efficacy of complementary and orthodox medicine in complementary and general practice patients. Health Educ Res 1995;10:395-405.

16. Eisenberg DM. Advising patients who seek alternative medical therapies. Ann Intern Med 1997;127:61-9.

17. Chez RA, Jonas WB. The challenge of complementary and alternative medicine. Am J Obstet Gynecol 1997;177:1156-61.

18. Jonas WB. Evaluating unconventional medical practices. J NIH Res 1993;5:64-7.

19. Rosenberg W, Donald A. Evidence based medicine: an approach to clinical problem-solving. BMJ 1995; 310:1122-6. 